\title{
Use of bioremediation for the removal of petroleum hydrocarbons from the soil: an overview
}

\author{
João Victor de Oliveira Santos ${ }^{1}$, Ylanna Larissa Alves Ferreira ${ }^{1}$, Letícia \\ Leôncio de Souza Silva ${ }^{1}$, Ingrid Miranda de Lacerda Buarque de Lyra ${ }^{1}$, Sarah \\ Brandão Palácio ${ }^{1}$, Isabella Macário Ferro Cavalcanti ${ }^{1,2}$
}

\author{
${ }^{1}$ Federal University of Pernambuco (UFPE), Keizo Asami Immunopathology Laboratory (LIKA), Recife, Pernambuco, \\ Brazil \\ ${ }^{2}$ Federal University of Pernambuco (UFPE), Laboratory of Microbiology and Immunology, Centro Acadêmico de Vitória \\ (CAV), Vitória de Santo Antão, Pernambuco, Brazil
}

\begin{abstract}
Large amount of organic and inorganic compounds are released constantly in the environment as a consequence of human activity and technological and industrial advancement. Environmental pollution by petroleum and petrochemicals, such as petroleum hydrocarbons (PHCs), is considered one of the most serious hazards today due to its worldwide distribution. Contamination by these pollutants causes degradation of global environment and a substantial reduction in biodiversity. In addition, a deep removal of the pollutants is often required to prevent their migration into the water, air and therefore threaten human health. In this way, the search for ecologically sustainable approaches to repair contaminated environments have been of great concern in society. Bioremediation is a technique, based on the metabolic activity of living organisms, which aims to reduce, degrade and/or remove contaminants from the marine and terrestrial ecosystems. It is a more economical and more efficient process to minimize waste, compared to the usual physical-chemical treatment methods. Historically, bioremediation has been used to restore environments polluted by PHCs, where microbial communities play a key role during this course, either by the direct degradation of pollutants or by interaction with other microorganisms. Finally, this review discusses about the soil contamination by PHCs, the role of living organisms in this mechanism and their recent application in bioremediation process.
\end{abstract}

Keywords- PHCs, pollutants, environment, remediation, microorganism.

\section{INTRODUCTION}

The pollution of the environment increases at an alarming rate. Large amounts of organic and inorganic compounds are released into the environment continuously, as a consequence of human activity, technological advance, and indiscriminate use of agricultural practices $[1,2]$. Crude oil contains a range of compounds toxic to humans and to the environment, including PHCs. Some compounds that are classified as PHCs are better known as BTEX (benzene, toluene, ethylbenzene and xylene). In terms of harmful effects on health, benzene is one of the most concerning compounds due to its carcinogenic effect. Long-term exposure to benzene may cause bone marrow abnormalities. Ethylbenzene is recognized as potentially carcinogenic since its inhalation increases the incidence of renal, testicular, and liver tumors. Toluene and xylene exhibit acute and chronic toxicity in the central nervous system of humans and animals $[3,4]$.

\subsection{Bioremediation}

Bioremediation is a technique that exploits the ability of living organisms to reduce, degrade and/or remove contaminants from marine and terrestrial ecosystems, thereby minimizing the risk to human health by restoring the ecosystem to its normal condition $[1,5,6]$. The fundamental principles of bioremediation involve reducing the solubility, redox reactions and the adsorption of contaminants from the polluted environment [7]. The success of this technique also depends on the nature of the pollutant, which may be hydrocarbons, heavy metals, agrochemicals, greenhouse gases, nuclear waste, sewage [8].

Bioremediation technologies are based on chemical oxidation/reduction reactions. These reactions modify the chemical composition, from the addition of reagents, generating an increase of the degradation and extraction of contaminants, converting them into less toxic, less mobile or inert compounds [7]. 
Depending on the application site, bioremediation techniques can be classified ex situ or in situ. In situ bioremediation implies a cleaning treatment of pollutants in their place of origin. It does not require excavation, therefore it results in little or no disturbance in soil structuring. This bioremediation has been successfully used in the treatment of hydrocarbons, heavy metals and dyes [7]. Ex situ bioremediation involves the excavation of the pollutants and subsequently transporting it to another treatment site. To choice the suitable technique which should be used, certain variables such as the type of pollutant, the degree of pollution and the geology of the contaminated site must be considered [8].

The usual in situ and ex situ physico-chemical treatments for remediation of PHCs involve costly strategies, and often result only in the incomplete decomposition of the pollutants. Thus, in the last two decades, alternative remediation techniques based on biological methods have been progressively accepted as a standard practice, since they are more efficient in minimizing waste and preserving natural resources, as well as being more costeffective [6,9].

Environmental pollution by oil and PHCs is considered one of the most serious current problems [10, 11]. Historically, bioremediation has been used for restoration of environments polluted by PHCs $[5,6,12]$. Bioremediation has become an alternative method of remediation of oil-contaminated areas, where microbial communities play a key role during the process, either by direct degradation of pollutants or by interaction with other microorganisms added [13]. However, environmental conditions such as temperature, substrate availability, presence of suitable microorganis ms, $\mathrm{pH}$ and humidity, directly influence the growth and metabolism of microorganisms, making these the main limiting factors for the success of bioremediation [7].

Many bacterial strains have been described capable of degrading PHCs, among them the species of Pseudomonas, Acinetobacter, Mycobacterium, Haemophilus, Rhodococcus, Paenibacillus and Ralstonia [14]. This ability is attributed to the presence of genes and enzymes that use chemical complexes present in petroleum as vital sources of energy. In some situations, these bacterial enzymes need the plants to remove the pollutants, a process that is called phytoremediation [15]. Phytobioremediation is an alternative of remediation of organic pollutants and contaminants of heavy metals, using plants and associated microorganisms, to metabolize and degrade contaminants found in the most varied habitats. Phytobioremediation is considered an efficient method because it is ecologically correct and economical, being a good alternative for the effects generated by the growth of the petroleum industry $[16$,
17]. However, the expected success depends on the level of contamination, amount of contaminating metal, as well as the absorption capacity of heavy metals by plants and microorganisms [6].

The treatment of contaminated soils through bioremediation involves two main strategies, biostimulation and bioaugmentation. Biostimulation consists of the manipulation of environmental variables, introducing essential nutrients or biosurfactants, in order to increase the degradation of PHCs by native microorganisms [5, 13]. The bioaugmentation is based on the increase of the microbial population with degradative capacities, through the addition of oil degrading microorganisms to the contaminated soil matrix. Bioremediation is ideal for circumstances in which native microorganisms cannot perform pollutant degradation. Both techniques can be applied separately or in combination [5, 18]. The diversity and abundance of microorganisms present in polluted environments directly affect the success of the remediation technique employed. Once the PHC removal process has started, the availability of the free contaminant and its potential to penetrate the membrane of the organism have determined the rate in which the contaminant can be absorbed by the microorganism [8].

\section{OIL HYDROCARBONS}

During the process of extraction, refining, storage and transport of PHCs, considerable amounts of this product are released into the environment, with spillage being the main route of contamination $[5,19]$. The need of oil and other compounds as alternative sources of energy has contributed to the increase in pollution resulting from this class of pollutants [8].

PHCs are organic pollutants of great concern due to its toxicity and extensive worldwide distribution. They are classified into two categories, diesel range hydrocarbons (DRHs) and gasoline-range hydrocarbons (GRHs). DRHs include longer chain alkanes and hydrophobic chemicals, such as polycyclic aromatic hydrocarbons (PHCs). GRHs include hydrocarbons, such as ethylbenzene, benzene, xylenes and toluene [6].

For more than half a century, procedures in the petrochemical industry have indiscriminately caused the release of hydrocarbons and related pollutants, causing degradation of the environment and a considerable reduction in soil biodiversity. It is not only a social and sanitary issue, but it is also an economic issue, by way of these problems are harmful to local populations living on agriculture, an important pillar for the world economy [3]. In addition, deep cleaning is often necessary in order to prevent the migration of contaminants into the water, air and hence threaten human health [5, 20]. Prolonged 
exposure to PHCs can impair the central nervous system and endocrine system, increasing the risk to develop bladder, kidney, lung and skin cancers [21-23]. The attempt to create an appropriate and effective protocol for decontamination by petrochemicals remains an enigma $[24,25]$. Factors such as the geological formation, composition and types of hydrocarbons found in different regions should be considered. Therefore, a single and unvarying approach does not seem appropriate. In view of this, the search for new ecologically sustainable approaches to repair environments contaminated with PHCs is of major importance [3]. Over the years, various researches have been published with technologies available to deal with contaminated soils. Bioremediation based on the metabolic activity of microorganisms for restoration of environments contaminated by a range of contaminants presents certain advantages. Nonetheless, a successful application for PHCs remains a challenge.

\section{BIOLOGICAL SOLUTIONS FOR CONTAMINATION}

The ability of certain microorganisms to utilize PHCs as a carbon source in their metabolism has been proven for about 80 years [18]. For the purpose of promote an efficient bioremediation of PHCs, it is necessary to add fertilizers rich in nitrogen $(\mathrm{N})$ and phosphorus $(\mathrm{P})$, as these elements promote the growth of the local microbial community $[6,26]$.

The degree of susceptibility of PHCs to different bioremediation techniques can be evaluated by understanding three parameters: (a) microbial properties (regulation and gene expression, metabolic diversity, adhesion mechanisms, metal tolerance, chemotaxis); (b) environmental factors (nutrient availability, salinity, pressure, temperature, $\mathrm{pH}$, water availability); and (c) hydrocarbon substrate properties (solubility, concentration, hydrophobicity, volatility, molecular mass) $[6,27,28]$.

Among the microorganisms with the capacity to restrain the hydrocarbons in the soil, bacteria and fungi stand out.

\subsection{Bacteria}

Bacteria are efficient microorganisms in the petroleum degradation process [29]. Certain bacteria such as Bacillus sp., Pseudomas sp. and Chomobacterium vinosum reduce the total hydrocarbons by the secretion of lipases that can hydrolyze the constituent fatty acids [30]. The P-1 strain of Pseudomonas sp. was able to degrade crude oil and hydrocarbons such as hexadecane. Bacteria of this genus are known for the ability to produce biosurfactants, which, together with the degradation capacity of PHCs, make them advantageous options in the bioremediation of contaminated soils [31]. Four species of biosurfactant-producing Pseudomonas: P. acidovorans,
P. cepacia, P. picketti and P. fluorescens, had the ability to remove $80 \%$ of motor oil present in the soil [32]. The strains of Bacilli, Bacillus stratosphericu, Bacillus subtilis, Ochrobactrum sp. and P. aeruginosa, isolated from the soil contaminated by creosote, present great potential for hydrocarbons degradation by the production of biosurfactants [33]. Bacillus subtilis besides producing surfactants, also has the ability to degrade hydrocarbons [34]. Both bacteria, P. aeruginosa sp. and B. subtilis, use PHCs as a source of carbon and energy. However, some studies found a greater activity when both were previously exposed to the pollutant $[35,36]$. Furthermore, these bacteria are used in tropical countries to treat contaminated soils, since they are thermophilic microorganisms [37]. Other studies reported the association of bacteria as a potent bioremediator. Two species of Sphingomonas, B0695 and EPA505 were evaluated for their bioremediate effect separately and in combination. When hydrocarbons are exposed to bacteria individually, only low-weight hydrocarbons (naphthalene, phenanthrene and fluoranthene) are degraded. However, all contaminants were degraded when exposed to both bacterial species simultaneously, indicating that the use of the associated species brings advantages in the bioremediation of contaminated soils [38, 39].

\subsection{Fungi}

Fungi play an important role in bioremediation due to their metabolic activity, ability to secrete enzymes and to survive in extreme environmental conditions. Thus, the use of fungi in bioremediation seems to be the sustainable and economical choice for the treatment of soils contaminated by toxic organic compounds [40]. White-rot fungi have a great potential for bioremediation. These fungi produce lignolytic enzymes, responsible for the adsorption of dyes, allowing their application in places that contain dyes in degradation and discoloration of organic pollutants. Coriolus versicolor, Hirschioporus larincinus, Inonotus hispidus, Phanerochaete chrysosporium, Phlebia tremellosa are some examples of these fungi. The evaluation of the activity of thirteen lignolytic fungal strains was performed and it was verified that the degree of degradation of aromatic hydrocarbons varied according to the amount of lignolytic enzymes [41]. Moreover, fungi are efficient in the reduction of phenolic compounds, and can be useful in the recovery of soils contaminated by PHCs. Fungi are excellent bioremediators of toxic compounds due to their ability to produce enzymes, such as lipases, that have the capacity to breaks-up highly stable aromatic rings presented in PHCs. Among fungi with potential for degradation of these compounds are Aspergillus, Curvularia, Drechslera, Fusarium, Lasiodiplodia, Mucor, Penicillium, Rhizopus and Trichoderma [42, 43]. Low 
molecular weight PHCs are easily degraded by Aspergillus sp., Fusarium oxysporum and Trichocladium canadense. On the other hand, the high molecular weight ones are degraded with higher potential by T. canadense, Aspergillus sp., Verticillium sp. and Achememonium sp. [44]. P. ostreatus also demonstrated the ability to remove PHCs, such as phenanthrene and pyrene [45]. The fungi present an intracellular network of cytochrome P450 (CYPs) that can be used as catalytic agent of the hydrocarbon oxidation process, being an important mechanism for the successful removal of PHCs [46]. Another mechanism of action of fungi is the production of laccases. Laccases belong to the group of blue oxidases, which use extracellular copper as cofactor and oxygen as co-substrate. Furthermore, they are able to oxidize phenolic and non-phenolic compounds, being observed with a higher activity in fungi [47]. Due to its activity upon a variety of substrates, laccases are considered an ideal catalyst for different industrial applications, such as the use of these enzymes for bioremediation, even in extreme conditions of salinity, permitting their application in the bioremediation of polluted soils and seas [48]. Phanerocheate chrysosporium and Aspergillus niger fungi produce enzymes that act on hydrocarbon substrates, allowing their efficient application in the process of removing residues from diesel contaminated soils [10].

\subsection{Earthworms}

Earthworms have been applied in the bioremediation since 1976, after having survived the ingestion of toxic products that leaked after explosion of a factory in Italy. Since then, researches have evaluated the potential of earthworms in bioremediation of soils contaminated with crude oil and by-products. E. eugeniae was not the only microorganism able to survive to the high concentration of contaminating diesel, it also reduced the concentration of heavy metals, PHCs and benzene, as well as completely eliminated toluene, ethylbenzene and xylene, adapting to the new soil conditions [3]. A similar result was observed when using Eisenia foetida in pyrene bioremediation [49]. Degradation rates increase when $E$. fetida was added to soil contaminated with heavy crude oil [50]. A study evaluating Eudrilis eugeniae in soil contaminated with hydrocarbons showed that a greater reduction in hydrocarbon content was obtained when compared to samples that were not exposed to the worm [24]. Soil contaminated with PHCs, phenanthrene and fluoranthene were rapidly bioremediated after exposure to the earthworm species Lumbricus rubellus when compared to microorganisms [51].

Nanomaterials: an alternative method to remove pollutants
The use of nanosystems to remove pollutants has important advantages. Nanomaterials have a much larger surface area compared to their total volume, which increases the area of interaction between the substances, the reactivity of reaction and the efficiency in the degradation of toxic compounds, reducing the amount of activation energy and shortening the latency after remediation [52].

Nanomaterials of different shapes and sizes can be applied for environmental remediation [52]. $\mathrm{TiO}_{2}$ nanotubes are useful in the degradation of pentachlorophenol (PCP), a fungicide and herbicide, toxic to humans [53]. Polyamidoamine dendrimers (PAMAM) are used for the treatment of water as they are considered efficient and harmless to human health [54]. Magnetic iron oxide nanoparticles (IONPs) can be linked to enzymes, such as trypsins and peroxides, to protect these enzymes from oxidation, increasing their shelf life from hours to weeks for them to act as catalysts for remediation process [55]. Laccases, short half-life enzymes capable of catalyzing the oxidation of a series of phenolic compounds, have already been encapsulated in nanoparticles to provide stability of these enzymes over a wide $\mathrm{pH}$ and temperature ranges [47]. In this way, polymeric nanoparticles consisted of amphiphilic polyurethane (APU) and containing laccases have high capacity to remove PHCs from the soil [48].

\section{CONCLUSION}

This review highlighted the effects of PHC contamination by certain human activities on the environment, possible health risks after long exposure, and characteristics of bioremediation process. The review also emphasized the potential use of microorganisms as biological tools, providing a more economical and efficient alternative to minimize waste and preserve natural resources, intend to be a promising solution to one of the crucial problems of modern society.

\section{REFERENCES}

[1] N.S. Kasture. (2017). Bioremediation of Nitroaromatics: An Overview. International Journal of Environment, Agriculture and Biotechnology (IJEAB) (ISSN: 2456-1878). 2(5), 2715-2719. 10.22161/ijeab/2.5.56.

[2] Abdus-Salam Nasiru, Ademola Olamide Sodiq, Oyewumi Musa Rukayat Titilayo. (2017). Bioremediation of Heavy Metals in Contaminated Soil from Abandoned Asa Dam Road Dumpsite. International Journal of Environment, Agriculture and Biotechnology (IJEAB) (ISSN: 2456-1878). 2(5), 2516-2523. 10.22161/ijeab/2.5.32 
[3] O. A. Ekperusi, F. I. Aigbodion. (2015). Bioremediation of petroleum hydrocarbons from crude oil- contaminated soil with the earthworm: hyperiodrilus africanus. 3 Biotech (ISSN: 2190 5738). 5(6), 957-965. 10.1007/s 13205-015-0298-1.

[4] Mansooreh Dehghania, Mehdi Fazlzadeh, Armin Sorooshianc, Hamid Reza Tabatabaeee, Mohammad Mirif, Abbas Norouzian Baghania, Mahdieh Delikhoonh, Amir Hossein, Mahvig, and Majid Rashidia. (2018). Characteristics and health effects of btex in a hot spot for urban pollution. Ecotoxicology and environmental safety (ISSN: 1090-2414). 135, 143.10.1016/j.ecoenv.2018.02.065.

[5] Francisco Gomez, Majid Sartaj. (2013). Field scale ex-situ bioremediation of petroleum contaminated soil under cold climate conditions. International biodeterioration \& biodegradation (ISSN: 0964 8305). 85; 375-382. 10.1016/j.ibiod.2013.08.003.

[6] Panagiotis Gkorezis, Matteo Daghio, Andrea Franzetti, Jonathan D. Van Hamme, Wouter Sillen, Jaco Vangronsveld. (2016). The interaction between plants and bacteria in the remediation of petroleum hydrocarbons: an environmental perspective. Frontiers in microbiology (ISSN:1664-302X). 7. 10.3389/fmicb.2016.01836.

[7] Omena Bernard Ojuederie, Olubukola Oluranti Babalola. (2017). Microbial and Plant-Assisted Bioremediation of Heavy Metal Polluted Environments: A Review. International journal of environmental research and public health (ISSN: 1660-4601). 14(12). 1504. 10.3390/ijerph14121504.

[8] Christopher Chibueze Azubuike, Chioma Blaise Chikere, Gideon Chijioke Okpokwasili. (2016). Bioremediation techniques-classification based on site of application: principles, advantages, limitations and prospects. World Journal of Microbiology and Biotechnology (ISSN: 15730972). 32(180). 10.1007/s 11274-016-2137-x.

[9] Mallavarapu Megharaj, Ravi Naidu. (2017). Soil and brownfield bioremediation. Microbial biotechnology (ISSN: $\quad$ 1751-7915). $\quad 10(5), \quad 1244-1249$. 10.1111/1751-7915.12840.

[10] Y. Avasn Maruthi, Kaizar Hossain, Sujata Thakre. (2013). Aspergillus flavus: A potential Bioremediator for oil contaminated soils. European Journal of Sustainable Development (ISSN: 2239 5938). 2(1), 57-66. 10.20897/ejosdr/85933.

[11] Xixi Lia, Fuqiang Fana, Baiyu Zhanga, Kedong Zhangb, Bing Chen. (2018). Biosurfactant enhanced soil bioremediation of petroleum hydrocarbons: Design of experiments (DOE) based system optimization and phospholipid fatty acid (PLFA) based microbial community analysis. International Biodeterioration \& Biodegradation (ISSN: 09648305). 132, 216-225. 10.1016/j.ibiod.2018.04.009.

[12] J. L. Stroud, G. I. Paton, K. T. Semple. (2007). Microbe-aliphatic hydrocarbon interactions in soil: implications for biodegradation and bioremediation. Journal of Applied Microbiology (ISSN:1364-5072). $102(5)$ 1239-1253.10.1111/j.13652672.2007.03401.x.

[13] Sebastián Fuentes, Bárbara Barra, J. Gregory Caporaso, Michael Seegera. (2016). From rare to dominant: a fine-tuned soil bacterial bloom during petroleum hydrocarbon bioremediation. Applied and Environmental Microbiology (ISSN: 1098-5336). 82(3), 888-96. 10.1128/AEM.02625-15.

[14] Meenu Tyagi, M. Manuela R. da Fonseca, Carla C. C. R. de Carvalho. (2011). Bioaugmentation and biostimulation strategies to improve the effectiveness of bioremediation processes. Biodegradation (ISSN: 22:231-241). 22(2). 10.1007/s 10532-010-9394-4.

[15] Sharyn Gaskin, Kathleen Soole, Richard Bentham. (2008). Screening of Australian Native Grasses for Rhizoremediation of Aliphatic HydrocarbonContaminated Soil. International Journal of Phytoremediation (ISSN: 378-389). 10(5). 10.1080/15226510802100465.

[16] Amarjyoti Sandhu, Larry J. Halverson, Gwyn A. Beattie. (2007). Bacterial degradation of airborne phenol in the phyllosphere. Environmental Microbiology (ISSN: $\quad 383-392) . \quad 9(2)$. 10.1111/j. 1462-2920.2006.01149.x.

[17] Walter W. Wenzel. (2009). Rhizosphere processes and management in plant-assisted bioremediation (phytoremediation) of soils. Plant and Soil (ISSN: 385-408). 321(1-2). 10.1007/s 11104-008-9686-1.

[18] Bijay Thapa, Ajay Kumar KC, Anish Ghimire. (2012). A Review on Bioremediation Of Petroleum Hydrocarbon Contaminants In Soil. Kathmandu University Journal of Science, Engineering and Technology (ISSN: 1816-8752). 8(1):164-70. 10.3126/kuset.v8i1.605.

[19] Gabriela Mercuri Quiterio, Jaqueline Matos Cruz, Renato Nalin Montagnolli, Ederio Dino Bidoia. (2017). Bioremediation of diesel / biodiesel blends in soil: a respirometric approach. African journal of biotechnology (ISSN: 1684-5315). 7(9).

[20] Qingmei Liu, Qibin Li, Ning Wang, Dan Liu, Li Zan, Le Chang, Xuemei Gou, Peijin Wang. (2018). Bioremediation of petroleum-contaminated soil using aged refuse from landfills. Waste Management (ISSN: $\quad$ 0956-053X). 77, 576-585. 10.1016/j. wasman.2018.05.010. 
[21] Michael S. Hutcheson, Dana Pedersen, Nicholas D. Anastas, John Fitzgerald, Diane Silverman. (1996). Beyond tph: health-based evaluation of petroleum hydrocarbon exposures. Regulatory toxicology and pharmacology (ISSN:1096-0295). 24(1), 85-101. 10.1006/rtph.1996.0066.

[22] Richard M. Locksley. (2010). Asthma and Allergic Inflammation. Cell (ISSN: 1097-4172). 140(6), 777783. 10.1016/j.cell.2010.03.004.

[23] Feng Xiong, Qin Li, Bo Zhou, Jiongli Huang, Guiqiang Liang, Li'e Zhang, Shuyan Ma, Li Qing, Linhan Liang, Jing Su, Xiaowu Peng, Qin Li, Yunfeng Zou. (2016). Oxidative Stress and Genotoxicity of Long-Term Occupational Exposure to Low Levels of BTEX in Gas Station Workers. International Journal of Environmental Research and Public Health (ISSN: 1660-4601). 13(12), 1-9. 10.3390/ije rph13121212.

[24] Alewo Opuada Ameh, Ibrahim Ali MohammedDabo, Sani Ibrahim, Joseph Baba Ameh, Yahuza Tanimu, Tajudeen Kolawole Bello. (2013). Effect of earthworm inoculation on the bioremediation of used engine oil contaminated soil. International Journal of Biological and Chemical Sciences (ISSN: 1991-8631). 6(1), 493-503. 10.4314/ijbcs.v6i1.44.

[25] Yang, C. F., Liu, S. H., Su, Y.M., Chen, Y.R., Lin, C. W., Lin, K. L. (2019). Bioremediation capability evaluation of benzene and sulfolane contaminated groundwater: Determination of bioremediation parameters. Science of The Total Environment (ISSN: $\quad$ 0048-9697). 648, 811-818. 10.1016/j.scitotenv.2018.08.208.

[26] Marc Viñas, Jordi Sabaté, María José Espuny and Anna M. Solanas. (2006). Bacterial Community Dynamics and Polycyclic Aromatic Hydrocarbon Degradation during Bioremediation of Heavily Creosote Contaminated Soil. Applied and Environmental Microbiology (ISSN: 1098-5336). 71(11), 7008- 7018.10.1128/AEM.71.11.70087018.2005.

[27] Jan Sikkema, Jan A. M. De Bont, Bert Poolman. (1995). Mechanisms of Membrane Toxicity of Hydrocarbons. Microbiological reviews (ISSN: 0146-0749). 59(2), 201-222.10.1016/0300483X(86)90004-1.

[28] Oxana Botalova, Jan Schwarzbauer, Tom Frauenrath, Larissa Dsikowitzky. (2009). Identification and chemical characterization of specific organic constituents of petrochemical effluents. Water Research (ISSN: 1879-2448). 43(5), 3797-3812. 10.1016/j. watres.2009.06.006.

[29] Nilanjana Das, Preethy Chandran. (2010). Microbial Degradation of Petroleum Hydrocarbon
Contaminants: An Overview. Biotechnology Research International (ISSN: 2090-3146). 2011, 114. 10.4061/2011/941810.

[30] Vrutika Patel, Anukriti Sharma, Rup Lal, Naif Abdullah Al-Dhabi, Datta Madamwar. (2016). Response and resilience of soil microbial communities inhabiting in edible oil stress/contamination from industrial estates. $B M C$ Microbiology (ISSN: 1471-2180), 16(50). 1-14, 10.1186/s 12866-016-0669-8.

[31] Magdalena Pacwa-Płociniczak, Grażyna Anna Płaza, Anna Poliwoda, Zofia Piotrowska Seget. (2014). Characterization of hydrocarbon-degrading and biosurfactant-producing Pseudomonas sp. P-1 strain as a potential tool for bioremediation of petroleumcontaminated soil. Environmental Science and Pollution Research (ISSN: 1614-7499). 21(15), 9385-9395. 10.1007/s 11356-014-2872-1.

[32] Elias J. Silva, Nathália Maria P. Rocha e Silva, Raquel D. Rufino, Juliana M. Luna, Ricardo O. Silva, Leonie A. Sarubbo. (2014). Characterization of a biosurfactant produced by Pseudomonas cepacia CCT6659 in the presence of industrial wastes and its application in the biodegradation of hydrophobic compounds in soil. Journal homepage $\begin{array}{llll}\text { (ISSN: } & \text { 2317-1545). } & 117 & \text { (6). }\end{array}$ 10.1016/j.colsurfb.2014.02.012.

[33] Fisseha Andualem Bezza, Evans M. Nkhalambayausi Chirwa. (2016). Biosurfactant-enhanced bioremediation of aged polycyclic aromatic hydrocarbons (PHCs) in creosote contaminated soil. Journal homepage (ISSN: 2317-1537). 144. 10.1016/j.chemosphere.2015.08.027.

[34] Eduardo J. Gudina, Jorge F. B. Pereira, Rita Costa, João A. P. Coutinho, José A. Teixeira, Lígia R. Rodrigues. (2013). Biosurfactant-producing and oildegrading Bacillus subtilis strains enhance oil recovery in laboratory sand-pack columns. Journal of Hazardous Materials (ISSN: 0304-3894). 261, 106- 113. 10.1016/j.jhazmat.2013.06.071.

[35] Radhika Chandankere, Jun Yao, Martin M.F. Choi, Kanaji Masakorala, Yu Chan. (2013). An efficient biosurfactant-producing and crude-oil emulsifying bacterium Bacillus methylotrophicus USTBa isolated from petroleum reservoir. Biochemical Engineering Journal (ISSN: 1369-703X). 74:46-53. 10.1016/j.bej.2013.02.018.

[36] E. Fosso Kankeu, S. Marx, A. Brink. (2017). Adaptation behaviour of bacterial species and impact on the biodegradation of biodiesel-diesel. Brazilian Journal of Chemical Engineering (ISSN: 0104-6632), 34(2), 469-480. 10.1590/01046632.20170342s20150491. 
[37] Kishore Das, Ashis K. Mukherjee. (2007). Crude petroleum-oil biodegradation efficiency of Bacillus subtilis and Pseudomonas aeruginosa strains isolated from a petroleum-oil contaminated soil from North East India. Bioresource Technology (ISSN:1873-2976). 98(7),1339-345. 10.1016/j.biortech.2006.05.032.

[38] T. B. Janikowski, D. Velicogna, M. Punt, A. J. Daugulis. (2002). Use of a two-phase partitioning bioreactor for degrading polycyclic aromatic hydrocarbons by a Sphingomonas sp. Applied Microbiology and Biotechnology (ISSN: 14320614). 59(2-3), 368-376. 10.1007/s00253-002-1011$\mathrm{y}$.

[39] Andrew J. Daugulis, Colleen M. McCracken. (2003). Microbial degradation of high and low molecular weight polyaromatic hydrocarbons in a two-phase partitioning bioreactor by two strains of Sphingomonas sp. Biotechnology Letters (ISSN: 1573-6776). 25(17):1441-4. 10.1023/A:1025007729355.

[40] Radhika Deshmukh, Anshuman A. Khardenavis, Hemant J. Purohit. (2016). Diverse Metabolic Capacities of Fungi for Bioremediation. Indian Journal of Microbiology (ISSN: 0973-7715). 56(3), 247-264. 10.1007/s 12088-016-0584-6.

[41] Andrea R. Clemente, Tania A. Anazawa, Lucia R. Durrant. (2001). Biodegradation of polycyclic aromatic hydrocarbons by soil fungi. Brazilian Journal of Microbiology (ISSN: 1517-8382). 32 (4). 10.1590/S1517-83822001000400001.

[42] Balaji V, Arulazhagan P, Ebenezer P. (2014). Enzymatic bioremediation of polyaromatic hydrocarbons by fungal consortia enriched from petroleum contaminated soil and oil seeds. Journal of Environmental Biology (ISSN: 0254-8704). 35(3), 521-529. 10.13140/2.1.1528.3846.

[43] Chang YT, Lee JF, Liu KH, Liao YF, Yang V. (2015). Immobilization of fungal laccase onto a nonionic surfactant-modified clay material: application to PAH degradation. Environmental Science and Pollution Research (ISSN: 09441344). 23(5), 4024-4035. 10.1007/s 11356-0154248-6.

[44] A.K. Haritash, C.P. Kaushik. (2009). Biodegradation aspects of Polycyclic Aromatic Hydrocarbons (PHCs): A review. Journal of Hazardous Materials (ISSN:0304- 3894). 169(3), 1-15. 10.1016/j.jhazmat.2009.03.137.

[45] Emilio Rosales, Marta Pazos, M. Ángeles Sanromán. (2013). Feasibility of Solid-State Fermentation Using Spent Fungi-Substrate in the Biodegradation of PHCs. Clean - Soil, Air, Water (ISSN: 18630669). 41(6), 610-615. 10.1002/clen.201100305.

[46] Sukanta S. Bhattacharya, Khajamohiddin Syed, Jodi Shann, Jagjit S. Yadav. (2013). A novel P450initiated biphasic process for sustainable biodegradation of benzo[a]pyrene in soil under nutrient sufficient conditions by the white rot fungus Phanerochaete chrysosporium. Journal of Hazardous Materials (ISSN: 0304-3894). 261: 67583. 10.1016/j.jhazmat.2013.07.055.

[47] Sanjay K. S. Patel, Vipin C. Kalia, Joon-Ho Choi, Jung-Rim Haw, In-Won Kim, Jung Kul Lee. (2014). Immobilization of laccase on $\mathrm{SiO} 2$ nanocarriers improves its stability and reusability. Journal of Microbiology and Biotechnology (ISSN: 17388872). 24(5), 639-47. 10.4010/jmb.1401.01025.

[48] Buddolla Viswanath, Bandi Rajesh, Avilala Janardhan, Arthala Praveen Kumar, Golla Narasimha. (2014). Fungal laccases and their applications in bioremediation. Enzyme research (ISSN: $\quad$ 2090-0414). $\quad 2014, \quad$ 1-21. $10.1155 / 2014 / 163242$.

[49] Hongwen Sun, Jieming Li, Cuiping Wang, Lei Wang, Yingying Wang. (2011). Soil and Sediment Contamination: An International Journal. Soil and Sediment Contamination (ISSN: 1532-0383). 20(6),617-630. 10.1080/15320383.2011.594106.

[50] Luke Martinkosky, Jaimie Barkley, Gabriel Sabadell, Heidi Gough, Seana Davidson. (2016). Earthworms (Eisenia fetida) demonstrate potential for use in soil bioremediation by increasing the degradation rates of heavy crude oil hydrocarbons. Science of the Total Environment (ISSN: 0048-9697). 580, 734743. 10.1016/j.scitotenv.2016.12.020.

[51] Wein-Chun Ma, J. Immerzeel, J. Bodt. (1995). Earthworm and Food Interactions on Bioaccumulation and Disappearance in Soil of Polycyclic Aromatic Hydrocarbons: Studies on Phenanthrene and Fluoranthene. Ecotoxicology and Environmental Safety (ISSN: 0147-6513). 32(3), 226-232. 10.1006/eesa.1995.1108

[52] Md. Rizwan, Man Singh, Chanchal K. Mitra, Roshan K. Morve. (2014). Ecofriendly Application of Nanomaterials: Nanobioremediation. Journal of Nanoparticles (ISSN: 1572-896X). 1-7. 10.1155/2014/431787.

[53] Xie Quan, Shaogui Yang, Xiuli Ruan, Huiming Zhao. (2005). Preparation of Titania Nanotubes and Their Environmental Applications as Electrode. Environmental Science \& Technology (ISSN: 15205851). 39(10), 3770-3775. 10.1021/es048684o.

[54] Sachin B. Undre, Man Singh, R. K. Kale, Md. Rizwan. (2013). Silibinin binding and release 
activities moderated by interstices of trimesoyl, tridimethyl, and tridiethyl malonate first-tier dendrimers. Journal of Applied Polymer Science (ISSN: $\quad$ 0021-8995). 130(5), 3537-3554. 10.1002/app.39466.

[55] Y. Qiang, A. Sharma, A. Paszczynski, D. Meyer. (2007). Conjugates of magnetic nanoparticleenzyme for bioremediation. Clean Technologies (ISSN: 2571-8797). 4, 95-98. 